\title{
Pulmonary Clearance of Norepinephrine in Lambs
}

\author{
BARBARA A. CHAPPELL, JAMES F. PADBURY, DAVID M. HABIB, ALMA M. MARTINEZ, \\ SIANG L. THIO, ELIZABETH E. BURNELL, AND JAMES A. HUMME \\ Department of Pediatrics, Harbor-UCLA Medical Center, Torrance, California 90509
}

\begin{abstract}
The lungs play an important role in the metabolism of vasoactive substances including endogenous amines. The role of pulmonary clearance of circulating norepinephrine has not been well defined in the young lamb (7-8 d of age). Using radiolabeled tracer norepinephrine in acutely instrumented lambs, we determined the in vivo pulmonary clearance and spillover rate of norepinephrine under baseline and hypoxic conditions. The fractional extraction of norepinephrine, the percent removed on a single pass through the pulmonary circulation, was $23 \pm 2 \%$. The corresponding pulmonary clearance rate was $61 \pm 10 \mathrm{~mL} /$ $\mathrm{kg} / \mathrm{min}$ and the net pulmonary norepinephrine removal rate was $0.41 \pm 0.14 \mathrm{nmol} / \mathrm{kg} / \mathrm{min}$. This clearance represented over $70 \%$ of whole body norepinephrine clearance. The spillover of synaptic norepinephrine was $0.22 \pm 0.13 \mathrm{nmol} /$ $\mathrm{kg} / \mathrm{min}$. During hypoxia, animals showed significant increases in pulmonary artery pressure and resistance. Fractional extraction of norepinephrine decreased to $16 \pm 3 \%$, $p<0.005$. Pulmonary clearance decreased to $31 \pm 7 \mathrm{~mL} /$ $\mathrm{kg} / \mathrm{min}$, and net pulmonary norepinephrine removal rate decreased to $0.27 \pm 0.07 \mathrm{nmol} / \mathrm{kg} / \mathrm{min}$. These results demonstrate that pulmonary clearance plays a significant role in norepinephrine clearance in 1-wk-old lambs. Alteration of norepinephrine clearance during physiologic states such as hypoxia may be important in the pathophysiology of altered pulmonary vascular resistance in newborn animals. (Pediatr Res 29: 93-97, 1991)
\end{abstract}

\section{Abbreviations}

ANOVA, analysis of variance

In many species including rat, rabbit, dog, and man, the lungs play a significant role in norepinephrine clearance (1-4). The endothelial cells lining the small pre- and postcapillary vessels of the lung remove norepinephrine from the blood by a sodiumand temperature-dependent saturable mechanism with a $\mathrm{Km}$ of approximately $1 \mu \mathrm{M}(5-7)$. This clearance is unique, having characteristics of both neuronal and extraneuronal uptake systems. For example, it is inhibited by cocaine and imipramine (inhibitors of neuronal uptake) as well as normetanephrine (a nonneuronal inhibitor) (6).

In the literature to date, pulmonary fractional extraction of norepinephrine has ranged from 7 to $65 \%$; that is, 7 to $65 \%$ of total circulating norepinephrine is removed on a single pass through the pulmonary circulation (8-10). Studies have been conducted using both in vitro (isolated perfused lung) and in vivo

Received April 6, 1990; accepted August 13, 1990.

Correspondence and reprint requests: Barbara A. Chappell, M.D., HarborUCLA Medical Center, Research Building \#1, Torrance, CA 90509.

Supported in part by USPHS Grants no. HD-18014 and HD-07013. techniques. Isolated perfused lung methods have been the major focus of investigations into pulmonary norepinephrine clearance; however, surgical denervation and relatively low flow rates have made extrapolation of these results to in vivo systems difficult $(11,12)$. Similarly, in vivo studies based solely on arteriovenous differences in endogenous norepinephrine concentrations are difficult to interpret and may underestimate the actual clearance of norepinephrine. Therefore, in vivo methods using radioactive tracers are preferred (2). These methods allow determination of both clearance and spillover of synaptic norepinephrine (2). In vivo adult animal studies using tritiated norepinephrine demonstrate fractional extractions of norepinephrine of 35 to $60 \%$ (13, 14).

Various pathophysiologic conditions may alter the pulmonary clearance and spillover of norepinephrine including hypoxia, hyperoxia, and pulmonary hypertension (15-17). Little is known about the effect of development on pulmonary norepinephrine clearance. The available literature on pulmonary clearance in developing animals comes from rabbit studies using in vitro, isolated perfused lung techniques $(16,18)$ and comparison of arteriovenous differences in human infants (19). The purpose of our study was to determine the pulmonary clearance and production rate of norepinephrine in young animals in vivo using radiotracer techniques and to determine the effect of hypoxia on pulmonary norepinephrine clearance and spillover.

\section{MATERIALS AND METHODS}

Animal studies. After approval by the Animal Care and Use Review Committee, lambs $(n=8)$ were housed in metabolic cages with the ewe and allowed to nurse ad libitum while acclimating to the laboratory environment for 1 to $2 \mathrm{~d}$ before the study. On the day of the study, lambs were sedated with $15 \mathrm{mg} /$ $\mathrm{kg}$ ketamine intramuscularly followed by continuous i.v. ketamine at $10 \mathrm{mg} / \mathrm{kg} / \mathrm{h}$. After tracheostomy under local anesthesia, lambs were paralyzed with pancuronium bromide $(0.1 \mathrm{mg} / \mathrm{kg})$ and ventilated with pressure-controlled ventilators. Initial ventilator settings were peak inspiratory pressure, $20 \mathrm{~cm} \mathrm{H} \mathrm{H}_{2} \mathrm{O}$; end expiratory pressure, $2 \mathrm{~cm} \mathrm{H}$ O; respiratory rate, 30 breaths/min; inspiratory time, $0.7 \mathrm{~s}$; and fractional inspired oxygen, 0.50 . Ventilation was adjusted to maintain arterial blood $\mathrm{pH}$ between 7.35 and $7.45, \mathrm{PO}_{2}$ between 17.3 and $21.3 \mathrm{kPa}(130-160 \mathrm{~mm}$ $\mathrm{Hg}$ ), and $\mathrm{PCO}_{2}$ between 4.0 and $5.3 \mathrm{kPa}(30-40 \mathrm{~mm} \mathrm{Hg})$. Core temperature was monitored continuously by rectal probe and euthermia was maintained by warming pads. A 5 Fr umbilical artery catheter (Argyle; Sherwood Medical, St. Louis, MO) was introduced into the right carotid artery and, under direct pressure monitoring, it was advanced into the left ventricle. Under direct pressure monitoring and fluoroscopic guidance, a 5 Fr SwanGanz flow-directed, balloon-tipped thermodilution catheter (American Edwards Laboratories, Irvine, CA) was advanced from the right jugular vein into the right ventricle and further advanced until the sampling port was positioned in the main pulmonary artery. Position of these catheters was verified contin- 
uously by direct pressure monitoring and intermittently as necessary with fluoroscopy. A peripheral i.v. catheter was inserted into the saphenous vein for infusion of tracer. Glucose was infused at a rate of $6 \mathrm{mg} / \mathrm{kg} / \mathrm{min}$. Total i.v. fluids including glucose, ketamine, hormone, and normal saline to maintain patency of catheters were given at a rate equal to $6.25 \mathrm{~mL} / \mathrm{kg} / \mathrm{h}$.

After $1 \mathrm{~h}$ of stabilization, an infusion of $7-{ }^{3} \mathrm{H}-\mathrm{l}$-norepinephrine (New England Nuclear, Boston, MA; $14.2 \mathrm{Ci} / \mathrm{mmol}$ ) was begun at $0.6 \mu \mathrm{Ci} / \mathrm{kg} / \mathrm{min}(0.046 \mu \mathrm{g} / \mathrm{kg} / \mathrm{min})$ and continued throughout the study. Heart rate, blood pressure, cardiac output, and pulmonary artery pressure were monitored continuously and recorded every 20 min throughout the study. After measurement of hemodynamic variables, simultaneous left ventricular and pulmonary artery blood samples were drawn for catecholamines, tracer analysis, and arterial blood gas determinations. All blood samples were immediately replaced with an equal quantity of heparinized maternal blood. After $1 \mathrm{~h}$ of tracer infusion, the lambs were made hypoxic by decreasing fractional inspired oxygen to $12-14 \%$ with the addition of nitrogen to the ventilation mixture. Sampling and hemodynamic monitoring was continued every 20 min during the subsequent 1 -h period of hypoxia.

After completion of the hypoxia studies, all lambs were killed by i.v. pentobarbital overdose $(100 \mathrm{mg} / \mathrm{kg})$. Before overdose, radioactive microspheres of $15 \mu \mathrm{m}$ diameter were infused into two lambs during hypoxia to determine blood flow distribution and rule out major intracardiac shunts. Microspheres labeled with ${ }^{46} \mathrm{Sc}$ and ${ }^{47} \mathrm{Co}$ were injected simultaneously over 2 min into the left ventricle and superior vena cava, respectively. At autopsy, the lungs were removed, and the carcass and lungs were incinerated and processed separately for measurement of radioactivity.

Analytical Techniques. Immediately after sampling, blood was placed in test tubes containing reduced glutathione and EGTA. Samples were centrifuged at $4^{\circ} \mathrm{C}$ at $2500 \times g$ for $5 \mathrm{~min}$. The plasma was separated and stored at $-70^{\circ} \mathrm{C}$ until assay within 2 wk.

Tracer analysis. For separation of tritiated norepinephrine from radioactive metabolites, plasma was extracted with alumina (20). One half $\mathrm{mL}$ of plasma was added to $50 \mathrm{mg}$ of acid-washed

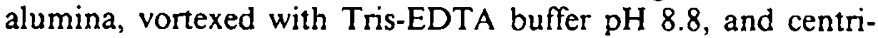
fuged, and the supernatant discarded. The alumina was washed three times with water, and $0.6 \mathrm{~mL}$ of $0.1 \mathrm{~N}$ perchloric acid was added and vortexed. After centrifugation, $0.4 \mathrm{~mL}$ of the eluate was added to $10 \mathrm{~mL}$ Scintiverse (Fisher Scientific, Springfield, NJ) scintillation cocktail and counted using a $\beta$-scintillation counter. Samples from individual animais were all extracted in the same assay along with an aliquot of the infusate. Recovery of radiolabeled norepinephrine averaged $60-70 \%$ as previously reported (20).

Catecholamine analysis. Plasma catecholamines were assayed in duplicate using a modification of the Peuler and Johnson method of catecholamine quantification (21). Samples from individual animals were all measured in the same assay. The sensitivity for norepinephrine is $0.12-0.24 \mathrm{nmol} / \mathrm{L}$ and for epinephrine is $110-220 \mathrm{pmol} / \mathrm{L}$, and the inter- and intraassay variabilities in our laboratory are each less than $5 \%$.

Microsphere techniques. After processing, 10 carcass aliquots of known mass and the entire lung were counted in a multichannel gamma spectrometer. Shunt fraction is expressed as the percentage of isotope crossover between carcass and lung.

Data analysis. Equations used for calculation of fractional extraction, specific organ clearance, and spillover have been described previously $(8,22)$.

Fractional extraction of norepinephrine (FextNE) was determined as follows:

$$
\begin{aligned}
\text { FextNE }(\%)=\left[{ }^{3} \mathrm{HNE}_{\mathrm{PA}_{\Lambda}}-{ }^{3} \mathrm{HNE}_{\mathrm{LV}}(\mathrm{cpm} / \mathrm{mL})\right] / \\
{ }^{3} \mathrm{HNE}_{\mathrm{P}_{\Lambda}}(\mathrm{cpm} / \mathrm{mL}) \times 100
\end{aligned}
$$

where ${ }^{3} \mathrm{HNE}_{\mathrm{PA}}$ and ${ }^{3} \mathrm{HNE}_{\mathrm{LV}}$ are the tracer concentrations in the pulmonary artery and left ventricle, respectively.
Pulmonary clearance of norepinephrine $(\mathrm{Cl})$ was determined as follows:

$$
\mathrm{Cl}(\mathrm{mL} / \mathrm{kg} / \mathrm{min})=\text { FextNE } \times \text { PPF }(\mathrm{mL} / \mathrm{kg} / \mathrm{min})
$$

where FextNE is derived in equation 1 and pulmonary plasma flow (PPF) is the cardiac output multiplied by ( 1 - hematocrit) and normalized to body weight.

Whole body plasma clearance rate (PCR) of norepinephrine was determined as follows:

$$
\begin{aligned}
\text { PCR }(\mathrm{mL} / \mathrm{kg} / \mathrm{min})=\left[{ }^{3} \mathrm{HNE}\right. \text { tracer } \\
\\
\times \text { infusion rate }(\mathrm{mL} / \mathrm{min})] /\left(\mathrm{d}^{3} \mathrm{HNE}_{\mathrm{PA}} \times \mathrm{wt}\right)
\end{aligned}
$$

where ${ }^{3} \mathrm{HNE}$ tracer $(\mathrm{cpm} / \mathrm{mL})$ is the radiolabeled norepinephrine concentration in the infusion and $\mathrm{d}^{3} \mathrm{HNE}_{\mathrm{PA}}(\mathrm{cpm} / \mathrm{mL})$ is the difference between the radiolabeled norepinephrine concentration in the pulmonary artery at each sampling time and preinfusion (i.e. background).

Net pulmonary removal of norepinephrine was determined as follows:

Removal ( $\mathrm{nmol} / \mathrm{kg} / \mathrm{min})$

$$
=\mathrm{NE}_{\mathrm{PA}}(\mathrm{nmol} / \mathrm{L}) \times \mathrm{Cl}(\mathrm{mL} / \mathrm{kg} / \mathrm{min}) / 1000 \mathrm{~mL} / \mathrm{L}
$$

where $\mathrm{NE}_{\mathrm{P} \wedge}$ is the endogenous norepinephrine concentration in the pulmonary artery and $\mathrm{Cl}$ is the pulmonary clearance determined in equation 2 .

Spillover of norepinephrine (Sp), reflecting egress from the synaptic cleft of norepinephrine released by pulmonary postganglionic sympathetic nerves, was determined as follows:

$$
\begin{aligned}
& \mathrm{Sp}(\mathrm{nmol} / \mathrm{kg} / \mathrm{min})=\left[\left(\mathrm{NE}_{\mathrm{LV}}-\mathrm{NE}_{\mathrm{PA}}\right)\right. \\
& \left.+\left(\mathrm{NE}_{\mathrm{PA}} \times \mathrm{FextNE}\right)\right](\mathrm{nmol} / \mathrm{L}) \times \mathrm{PPF}(\mathrm{L} / \mathrm{kg} / \mathrm{min})
\end{aligned}
$$

where $\mathrm{NE}_{\mathrm{LV}}$ is the endogenous norepinephrine concentration in the left ventricle.

Statistical analysis. All catecholamine concentrations were log transformed before statistical analysis and are expressed as geometric mean $\pm \mathrm{SEM}, \mathrm{pg} / \mathrm{mL}$. All biophysical measurements are presented as mean \pm SEM. Comparisons of hemodynamic pa-

Table 1. Arterial blood gases, hemodynamic parameters, and plasma catecholamine concentrations from preinfusion, baseline, and hypoxia*

\begin{tabular}{lccc}
\hline & Preinfusion & $\begin{array}{c}\text { Baseline } \\
\text { infusion }\end{array}$ & Hypoxia \\
\hline $\mathrm{pH}$ & $7.42 \pm 0.02$ & $7.41 \pm 0.01$ & $7.40 \pm 0.01$ \\
$\mathrm{CO}_{2}(\mathrm{kPa})$ & $4.5 \pm 0.2$ & $4.7 \pm 0.1$ & $4.3 \pm 0.1 \dagger$ \\
$\mathrm{O}_{2}(\mathrm{kPa})$ & $19.5 \pm 0.7$ & $18.5 \pm 0.5$ & $6 \pm 0.4 \ddagger$ \\
Heart rate & $190 \pm 13$ & $203 \pm 8$ & $230 \pm 13 \dagger$ \\
Cardiac output & $356 \pm 33$ & $328 \pm 21$ & $362 \pm 21$ \\
$\quad(\mathrm{~mL} / \mathrm{kg} / \mathrm{min})$ & & & \\
$\mathrm{PPF}(\mathrm{mL} / \mathrm{kg} / \mathrm{min})$ & $225 \pm 22$ & $250 \pm 15$ & $237 \pm 16$ \\
$\mathrm{PAP}(\mathrm{mm} \mathrm{Hg})$ & $12 \pm 1$ & $12 \pm 1$ & $21 \pm 2$ \\
$\mathrm{PVR}(\mathrm{mm} \mathrm{Hg} / \mathrm{mL} /$ & $0.019 \pm 0.005$ & $0.027 \pm 0.004$ & $0.046 \pm 0.005 \S$ \\
$\quad \mathrm{kg} / \mathrm{min})$ & & & \\
$\mathrm{NE}_{\mathrm{pa}}(\mathrm{nmol} / \mathrm{L})$ & $6.34 \pm 1.26$ & $5.51 \pm 0.89$ & $7.56 \pm 1.04 \dagger$ \\
$\mathrm{EPI}_{\mathrm{pa}}(\mathrm{pmol} / \mathrm{L})$ & $2150 \pm 310$ & $2100 \pm 300$ & $2350 \pm 610$ \\
\hline
\end{tabular}

* Abbreviations: PPF, pulmonary plasma flow; PAP, pulmonary arterial pressure; $P V R$, pulmonary vascular resistance; $\mathrm{NE}_{\mathrm{pa}}$, norepinephrine pulmonary artery concentration; $\mathrm{EPI}_{\mathrm{pa}}$, epinephrine pulmonary artery concentration. All values are mean $\pm S E M$ except $N_{p a}$ and $E P I_{p a}$, which are geometric mean \pm SEM. Values represent pooled average from preinfusion measurements, measurements during baseline radiolabelednorepinephrine infusion, and measurements during hypoxia. See Materials and Methods for further explanation of experimental detail.

$\dagger p<0.05$.

$\ddagger p<0.0001$

$\S p<0.0005$. 

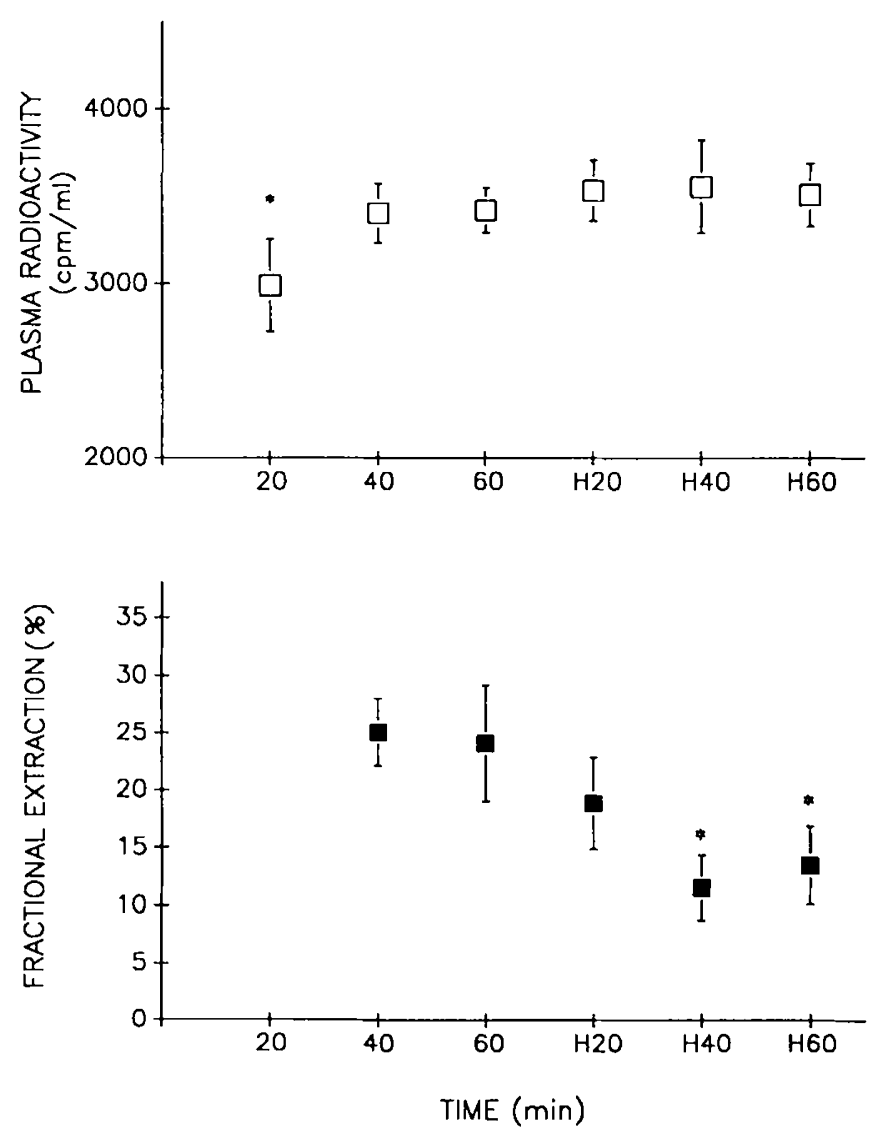

Fig. 1. Upper panel, plasma radioactivity during tritiated norepinephrine infusion at 20,40, and $60 \mathrm{~min}$ of baseline and 20,40, and $60 \mathrm{~min}$ of hypoxia $(H)$ (mean $\pm \mathrm{SEM}) .{ }^{*}$ Different from baseline at $p<0.05$. Lower panel, fractional extraction of norepinephrine during infusion of radiolabeled norepinephrine under baseline and hypoxic $(H)$ conditions (mean \pm SEM). * Different from baseline at $p<0.05$.

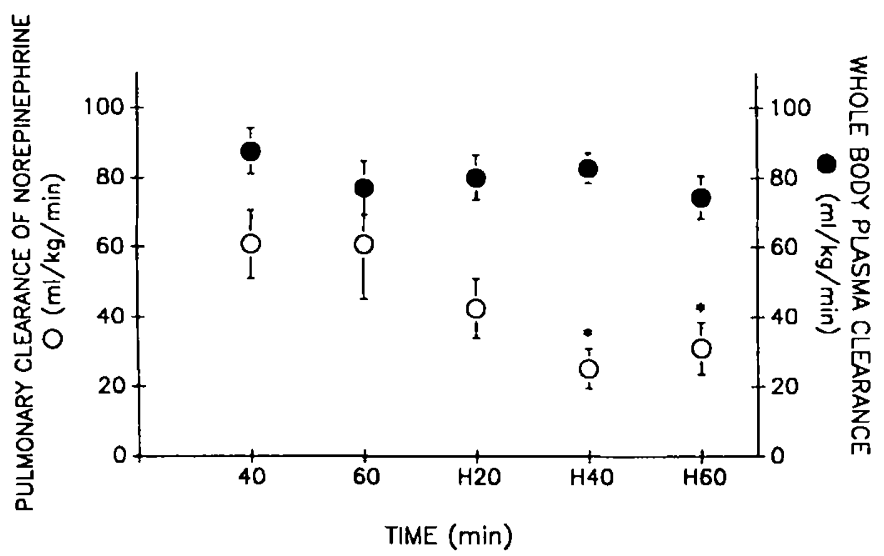

Fig. 2. Whole body and pulmonary clearance of norepinephrine under baseline and hypoxic $(H)$ conditions (mean \pm SEM). ${ }^{*}$ Different from baseline at $p<0.05$.

rameters and catecholamine levels under baseline and hypoxic conditions were made by two-level one-way ANOVA or paired $t$ test as appropriate.

\section{RESULTS}

Eight lambs were studied at 7 to $8 \mathrm{~d}$ of age. Mean weight was $5.2 \pm 0.4 \mathrm{~kg}$. Before the initiation of the radioactive hormone infusion, all animals were stable with heart rate, mean pulmonary artery pressure, cardiac output, pulmonary plasma flow, arterial

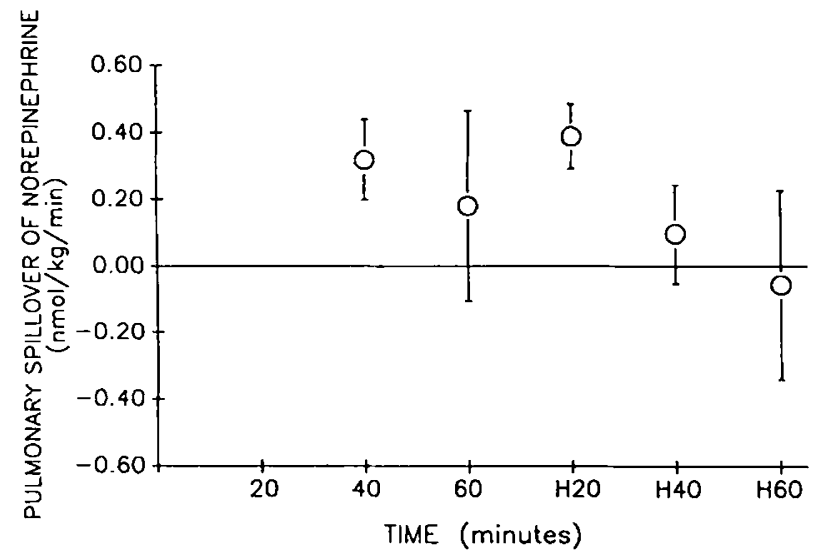

Fig. 3. Pulmonary spillover of norepinephrine under baseline and hypoxic $(H)$ conditions (mean \pm SEM).
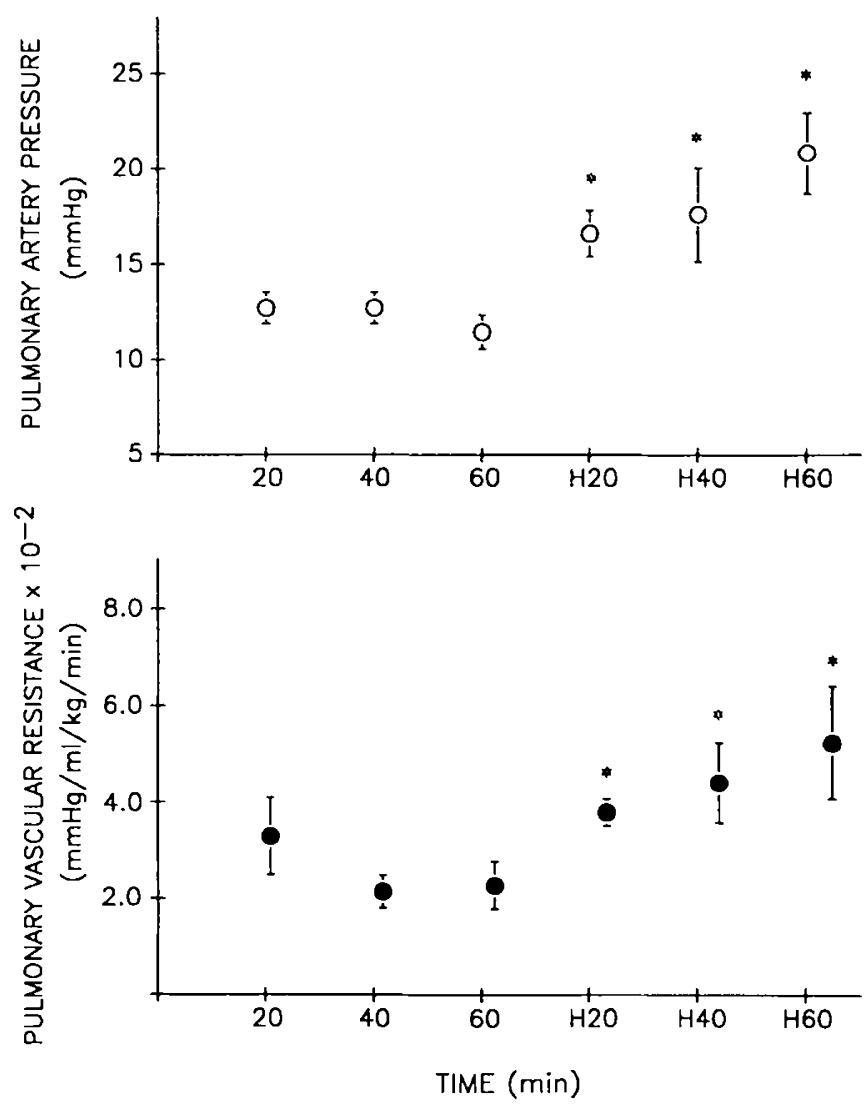

Fig. 4. Upper panel, pulmonary artery pressure under baseline and hypoxic $(H)$ conditions (mean \pm SEM). ${ }^{*}$ Different from baseline at $p<$ 0.005 . Lower panel, calculated pulmonary vascular resistance under baseline and hypoxic $(H)$ conditions (mean \pm SEM). ${ }^{*}$ Different from baseline at $p<0.005$ ).

blood gases, systemic systolic blood pressure, and pulmonary artery norepinephrine and epinephrine concentrations within expected ranges (23). These data are shown as preinfusion values in Table 1.

Plasma radioactivity and pulmonary clearance estimates during the tracer infusion are shown in Figure 1. Consistent with previous studies, the radiolabeled norepinephrine did not elevate the norepinephrine concentration significantly nor did it produce pharmacologic effects (2). During the infusion of radiolabeled norepinephrine, there were no changes in heart rate, blood pressure, and cardiac output when compared by one-way ANOVA. By $20 \mathrm{~min}$ of infusion during the baseline period, the plasma radioactivity had not yet reached steady state (Fig. $1 A$ ). 
By $40 \mathrm{~min}$, however, all animals had steady state plasma radioactivity. The simultaneous fractional extractions are shown in Figure $1 B$. The pulmonary clearance and whole body clearance estimates are shown in Figure 2. Because radioactivity, fractional extraction, and clearance were constant after $20 \mathrm{~min}$ (ANOVA), the averages were pooled from the $40-$ and $60-\mathrm{min}$ data. Mean fractional extraction of norepinephrine was $23 \pm 2 \%$ and pulmonary norepinephrine clearance was $61 \pm 10 \mathrm{~mL} / \mathrm{kg} / \mathrm{min}$. Whole body plasma clearance of norepinephrine was $78 \pm 3$ $\mathrm{mL} / \mathrm{kg} / \mathrm{min}$. Thus, under baseline conditions, pulmonary clearance constituted over $70 \%$ of whole body plasma clearance. Net pulmonary norepinephrine removal rate, which is a reflection of the pulmonary clearance and the concentration of circulating amine, was $0.41 \pm 0.14 \mathrm{nmol} / \mathrm{kg} / \mathrm{min}$. Pulmonary norepinephrine spillover is shown in Figure 3. The spillover rate during the baseline period from 40 to $60 \mathrm{~min}$ was $0.22 \pm 0.14 \mathrm{nmol} / \mathrm{kg} /$ min.

After the onset of hypoxia, $\mathrm{PO}_{2}$ decreased significantly from 18.5 to $6 \mathrm{kPa}(139$ to $45 \mathrm{~mm} \mathrm{Hg}, p<0.001) ; \mathrm{PCO}_{2}$ decreased slightly $(p<0.05)$. Pulmonary artery pressure and calculated pulmonary vascular resistance are shown in Figure 4. During the baseline norepinephrine tracer infusion, both pulmonary artery pressure and vascular resistance were stable. After the onset of hypoxia, mean pulmonary artery pressure rose steadily from 12 to $21 \mathrm{~mm} \mathrm{Hg}$, and pulmonary vascular resistance rose from 0.027 to $0.046 \mathrm{~mm} \mathrm{Hg} / \mathrm{mL} / \mathrm{kg} / \mathrm{min}(p<0.005)$. Systolic blood pressure also increased significantly from 126 to $145 \mathrm{~mm} \mathrm{Hg}$ and heart rate increased from 203 to 230 beats/min (Table 1) ( $p$ $<0.05$ ). All other physiologic measures, including $\mathrm{pH}$, pulmonary plasma flow, and cardiac output, were not significantly different between baseline and hypoxia.

During hypoxia, pulmonary artery norepinephrine concentration increased from $5.51 \pm 0.89$ to $7.56 \pm 1.04 \mathrm{nmol} / \mathrm{L}(p<$ $0.05)$; pulmonary artery epinephrine concentration was unchanged (Table 1). During hypoxia, fractional extraction of norepinephrine decreased significantly from $23 \pm 2$ to $16 \pm 3 \%$ $(p<0.05$; Fig. $1 B$ ). Pulmonary norepinephrine clearance decreased from $61 \pm 10$ to $31 \pm 7 \mathrm{~mL} / \mathrm{kg} / \mathrm{min}(p<0.05$, Fig. $2 A)$ and represented only $40 \%$ of whole body plasma clearance of norepinephrine, which did not change (Fig. $2 B$ ). Net pulmonary norepinephrine removal decreased from $0.41 \pm 0.14$ to $0.27 \pm$ $0.7 \mathrm{nmol} / \mathrm{kg} / \mathrm{min}(45 \pm 12 \mathrm{ng} / \mathrm{kg} / \mathrm{min} ; p<0.05)$. Pulmonary norepinephrine spillover was more variable between subjects and did not change (Fig. 3).

Microsphere determination of blood flow distribution showed a small (10\%) left to right shunt consistent with previous descriptions of bronchial flow and no right to left shunt within the limits of detection (24).

\section{DISCUSSION}

In our study, we demonstrated significant pulmonary extraction of circulating norepinephrine in 1 -wk-old lambs. Although the in vitro pulmonary clearance of norepinephrine has been demonstrated previously, these data compose the first description of pulmonary norepinephrine clearance in developing animals using in vivo radiolabeled tracer techniques. We also demonstrated a significant diminution in fractional extraction of norepinephrine with hypoxia. With the decrease in fractional extraction, pulmonary norepinephrine clearance decreased but spillover was unchanged.

Pulmonary clearance of norepinephrine has been determined in vitro and in vivo. Isolated perfused lung preparations using adult animals have suggested baseline fractional extraction rates of $30-53 \%(11,12,18)$. These studies demonstrate that pulmonary clearance of norepinephrine decreases with increasing concentrations of norepinephrine, suggesting that pulmonary uptake of norepinephrine is saturable at high rates of substrate delivery (11). In vivo studies based solely on arteriovenous differences of endogenous amine are difficult to interpret because the rich postganglionic sympathetic innervation of the lung may release norepinephrine into the blood, masking clearance. Based on arteriovenous differences of endogenous amine alone, the apparent pulmonary fractional extraction of norepinephrine in humans has varied from 0 to $27 \%$ under baseline conditions (17, 24-26). Data from in vivo protocols using nonradioactive norepinephrine infusions require doses that result in significant pharmacologic effects $(2,10)$. To avoid the pharmacologic effects of infused norepinephrine, steady state radiolabeled $l$-norepinephrine is currently the preferred method of determining norepinephrine clearance and spillover in vivo. Small amounts of exogenous radiolabeled norepinephrine may be detected without significantly increasing the circulating hormone concentration. Using tritium-labeled norepinephrine in adults, Esler and colleagues estimated pulmonary fractional extraction at $41 \%$, corresponding to a pulmonary norepinephrine clearance of 906 $\mathrm{mL} / \mathrm{min}$ and spillover of $0.94 \mathrm{nmol} / \mathrm{min}$ (12).

Pathophysiologic conditions including hypoxia, hyperoxia, drugs, and pulmonary hypertension alter pulmonary clearance of norepinephrine. Gewitz and Tait (16) demonstrated a decrease in in vitro pulmonary norepinephrine clearance in rabbit pups after $3 \mathrm{~d}$ of hypoxia. Hyperoxia exceeding $24 \mathrm{~h}$ also decreases pulmonary clearance of norepinephrine, suggesting that norepinephrine clearance may be a marker for oxygen-induced pulmonary endothelial damage (15). In vivo studies also suggest that norepinephrine clearance may be used as a marker for pulmonary toxicity of drugs (14). Based on arteriovenous differences of endogenous amine, pulmonary hypertension decreases pulmonary norepinephrine clearance in both adults and children to values approaching zero clearance $(17,19,27)$. It is unclear whether these findings represent a decrease in pulmonary clearance or an increase in spillover rate.

We showed a decreased fractional extraction of norepinephrine with hypoxia and elevated pulmonary artery pressure. It is important to note that only a modest degree of hypoxia was used to avoid major alterations in acid-base status. Nonetheless, a significant impact on the fractional extraction of norepinephrine and pulmonary norepinephrine clearance was observed. In contrast to previous studies, the duration of hypoxia and increased pulmonary artery pressure in our study was measured in minutes, not days or longer. By $40 \mathrm{~min}$, fractional extraction was significantly decreased. This rapid decrease in fractional extraction cannot be attributed to vascular endothelial remodeling, as in chronic pulmonary hypertension, and most likely represents intrapulmonary shunting of norepinephrine away from the pericapillary vessels active in norepinephrine metabolism. The decrease also may represent a saturation of the clearance mechanism or an effect of decreased oxygen on the uptake kinetics; however, the mild degree of hypoxia used and the mild increase in norepinephrine concentration make shunting a more likely explanation. While fractional extraction and pulmonary clearance of norepinephrine significantly decreased during hypoxia, net pulmonary norepinephrine removal also decreased significantly but to a lesser degree. The absence of a larger decrease in net pulmonary norepinephrine removal may be explained by an increase in substrate delivery during the hypoxic period. Spillover, an indirect index of pulmonary sympathetic activity, was variable between animals and did not change with hypoxia. The lack of an increase in pulmonary norepinephrine spillover was unexpected. The pulmonary vasculature has a rich sympathetic innervation and sympathectomy abolishes the pulmonary vasoconstriction response to hypoxia in lambs of this age but not older animals (28). The lack of increase in norepinephrine spillover could suggest that pulmonary sympathetic activity does not increase with this degree of hypoxia, or might be related to altered blood flow distribution in the areas of sympathetic vasoconstriction and lack of norepinephrine washout from innervated, lesser perfused areas. Finally, the spillover data may relate in part to the sensitivity of the use of blood samples to detect 
altered norepinephrine secretion kinetics at the actual neuroeffector junction.

In summary, the pulmonary vascular bed of 1-wk-old lambs extracts $20-25 \%$ of norepinephrine from the circulation. This extraction represents a contribution of over $70 \%$ to whole body clearance. With acute hypoxia, the pulmonary arterial pressures and pulmonary vascular resistance increase. The fractional extraction of norepinephrine and pulmonary norepinephrine clearance decrease. It is unclear from these data whether a greater impairment of pulmonary norepinephrine clearance would result from greater degrees of hypoxia and/or asphyxia. Decreased pulmonary norepinephrine clearance may result in increased norepinephrine delivery to resistance vessels within the pulmonary vasculature and to the systemic circulation and may contribute to the lability of vascular resistance in the neonatal period.

\section{REFERENCES}

1. Boileau JC, Campeau L, Biron P 1972 Pulmonary fate of intravenous norepinephrine. Rev Can Biol 31:185-192

2. Esler M, Jackman G, Bobik A, Kelleher D, Jennings G, Leonard P, Skews $H$ Korner $P 1979$ Determination of norepinephrine apparent release rate and clearance in humans. Life Sci 25:1461-1470

3. Nicholas TE, Strum JM, Angelo LS, Junod AF 1974 Site and mechanism of uptake of 'H-1-norepinephrine by isolated perfused rat lungs. Circ Re 35:670-685

4. Starjne L, Mathe KA, Mathe A, Birke G 1975 Specific and unspecific removal of circulating noradrenaline in pulmonary and systemic vascular beds in man. Acta Physiol Scand 95:46-53

5. Bakhle YS 1976 The inactivation of endogenous amines in lung. Agents Actions 6:505-509

6. Bakhle YS, Vane JR 1977 Metabolic functions of the lung. Marcel Dekker, New York

7. Iwasawa Y, Gillis CN, Agahajanian G 1973 Hypothermic inhibition of 5 hydroxytryptamine and norepinephrine uptake by lung: cellular location of amines after uptake. J Pharmacol Exp Ther 186:498-507

8. Esler M, Jennings G, Korner P, Blombery P, Sacharias N, Leonard P 1984 Measurement of total and organ-specific norepinephrine kinetics in humans. Am J Physiol 247:E21-E28

9. Henriksen JH, Christensen NJ, Ring-Larsen H 1986 Pulmonary extraction of circulating noradrenaline in man. Eur J Clin Invest 16:423-427

10. Sumikawa K, Hirano H 1986 Quantitative analysis of the contribution of pulmonary and hindlimb circulation to the clearance of exogenous catecholamines. J Pharmacol Exp Ther 236:759-763
11. Gillis $\mathrm{CN}$, Iwasawa $Y 1972$ Technique for measurement of norepinephrine and 5-hydroxytryptamine uptake by rabbit lung. J Appl Physiol 33:404-408

12. Roth RA 1982 Flow dependence of norepinephrine extraction by isolated perfused rat lungs. Am J Physiol 242:H844-H848

13. Catravas JD, Gillis CN 1983 Single-pass removal of $\left[{ }^{14} \mathrm{C}\right]-5$-hydroxytryptamine and $\left[{ }^{3} \mathrm{H}\right]$ norepinephrine by rabbit lung, in vivo: kinetics and sites of removal. J Pharmacol Exp Ther 24:28-33

14. Catravas JD, Lazo JS, Gillis CN 1981 Biochemical markers of bleomycin toxicity: clearance of $\left[{ }^{14} \mathrm{C}\right]-5$-hydroxytryptamine and $\left[{ }^{3} \mathrm{H}\right]$ norepinephrine by rabbit lung in vivo. J Pharmacol Exp Ther 217:524-529

15. Block ER, Cannon JK 1972 Effect of oxygen exposure on lung clearance of amines. Lung 55:287-295

16. Gewitz MH, Tait MS 1984 Effects of hypoxia on norepinephrine uptake by developing rabbit lung. Pediatr Pharmacol 4:109-113

17. Sole MJ, Drobac M, Schwartz L, Hussain MN, Vaughan-Neil EF 1979 The extraction of circulating catecholamines by the lungs in normal man and in patients with pulmonary hypertension. Circulation 60:160-163

18. Olson EB, DeWolf RE, Rankin J 1983 Uptake and metabolism of norepinephrine in isolated perfused fetal, newborn and adult rabbit lungs. Life Sci 32:321-327

19. Abman SM, Schaffer MS, Wiggins R, Washington R, Manco-Johnson RR, Wolfe RR 1987 Pulmonary vascular extraction of circulating norepinephrine in infants with bronchopulmonary dysplasia. Pediatr Pulmonol 3:386-391

20. Anton A, Sayre D 1962 A study of the factors affecting the aluminum oxidetrihydroxyindole procedure for the analysis of catecholamines. J Pharmacol Exp Ther 138:360-375

21. Peuler JD, Johnson GA 1977 Simultaneous single isotope radioenzymatic assay of plasma norepinephrine, epinephrine and dopamine. Life Sci 21:625636

22. Brush Jr JE, Eisenhofer G, Garty M, Stull R, Maron BJ, Cannon RO, Panza JA, Epstein SE, Goldstein DS 1989 Cardiac norepinephrine kinetics in hypertrophic cardiomyopathy. Circulation 79:836-844.

23. Lister G, Walter TK, Versmold HT, Dallman PR, Rudolph AM 1979 Oxygen delivery in lambs: cardiovascular and hematologic development. Am J Physiol 237:H668-H675

24. Rudolph AM 1985 Distribution and regulation of blood fow in the fetal and neonatal lamb. Circ Res 57:811-821

25. Gewitz M, Pitt BR, Laks H, Hammond GL, Tainer NS, Gillis CN 1982 Reversible changes in norepinephrine extraction by the lungs in children with pulmonary hypertension. Pediatr Pharmol 2:57-63

26. Peronnet F Beliveau L, Boudreau G, Trudeau F, Brisson G, Nadeau R 1988 Regional plasma catecholamine removal and release at rest and exercise in dogs. Am J Physiol 254:R663-R672

27. Russell WJ, Frewin DB, Jonsson JR 1982 Pulmonary extraction of catecholamines in critically ill patients. Anaesthesiol Intensive Care Med 10:319323

28. Custer JR, Hales CA 1986 Chemical sympathectomy decreases alveolar hypoxic vasoconstriction in lambs but not in sheep. J Appl Physiol 60:32-37 